\title{
INFLUENCE OF PHYSICO-CHEMICAL MATERIAL CHARACTERISTICS ON STAPHYLOCOCCAL BIOFILM FORMATION - A QUALITATIVE AND QUANTITATIVE IN VITRO ANALYSIS OF FIVE DIFFERENT CALCIUM PHOSPHATE BONE GRAFTS
}

\author{
M. Clauss ${ }^{1,2,3, *}$, U. Furustrand Tafin ${ }^{4}$, B. Betrisey ${ }^{3}$, N. van Garderen ${ }^{2}$, A. Trampuz ${ }^{3,5}$, T. Ilchmann ${ }^{1}$ and M. Bohner ${ }^{2}$ \\ ${ }^{1}$ Clinic for Orthopaedics and Trauma Surgery, Kantonsspital Baselland, Liestal, Switzerland \\ ${ }^{2}$ RMS Foundation, Bettlach, Switzerland \\ ${ }^{3}$ Infectious Diseases Service, Department of Internal Medicine, University Hospital Lausanne (CHUV), \\ Lausanne, Switzerland \\ ${ }^{4}$ Septic Surgical Unit, University Hospital Lausanne (CHUV), Lausanne Switzerland \\ ${ }^{5}$ Department for Traumatology and Reconstructive Surgery, Charité, Berlin, Germany
}

\begin{abstract}
Various compositions of synthetic calcium phosphates $(\mathrm{CaP})$ have been proposed and their use has considerably increased over the past decades. Besides differences in physicochemical properties, resorption and osseointegration, artificial CaP bone graft might differ in their resistance against biofilm formation. We investigated standardised cylinders of 5 different $\mathrm{CaP}$ bone grafts (cyclOS, chronOS (both $\beta$-TCP (tricalcium phosphate)), dicalcium phosphate (DCP), calcium-deficient hydroxyapatite (CDHA) and $\alpha$-TCP). Various physico-chemical characterisations e.g., geometrical density, porosity, and specific surface area were investigated. Biofilm formation was carried out in tryptic soy broth (TSB) and human serum (SE) using Staphylococcus aureus (ATCC 29213) and S. epidermidis RP62A (ATCC 35984). The amount of biofilm was analysed by an established protocol using sonication and microcalorimetry. Physico-chemical characterisation showed marked differences concerning macro- and micropore size, specific surface area and porosity accessible to bacteria between the 5 scaffolds. Biofilm formation was found on all scaffolds and was comparable for $\alpha$-TCP, chronOS, CDHA and DCP at corresponding time points when the scaffolds were incubated with the same germ and/or growth media, but much lower for cyclOS. This is peculiar because cyclOS had an intermediate porosity, mean pore size, specific surface area, and porosity accessible to bacteria. Our results suggest that biofilm formation is not influenced by a single physico-chemical parameter alone but is a multi-step process influenced by several factors in parallel. Transfer from in vitro data to clinical situations is difficult; thus, advocating the use of cyclOS scaffolds over the four other $\mathrm{CaP}$ bone grafts in clinical situations with a high risk of infection cannot be clearly supported based on our data.
\end{abstract}

Keywords: Biofilm; calcium phosphate; $\beta$-TCP; $S$. aureus ATCC 29213; S. epidermidis RP62A ATCC 35984; microcalorimetry; sonication; bone graft.

*Address for correspondence:

Martin Clauss

Kantonsspital Baselland Liestal,

Clinic for Orthopaedics and Trauma Surgery

Rheinstrasse 26

CH-4410 Liestal, Switzerland

Telephone Number: +41619253722

FAX Number: +41619252808

Email: martin.clauss@ksbl.ch
Introduction

More than one million patients per year need a bone grafting procedure to repair a bone defect resulting from a trauma or a bone disease. The use of autologous cancellous bone grafts transplanted as fresh bone grafts is regarded as the gold standard (Delloye et al., 2007; Ketonis et al., 2010). However, several bone graft substitutes have been proposed, such as fresh-frozen allogeneic cancellous bone grafts (Van de Pol et al., 2007; Kappe et al., 2010) and processed human or bovine cancellous bone grafts (Tadic and Epple, 2004). All these genuine bone grafts have a comparable calcium phosphate $(\mathrm{CaP})$ architecture (Clauss et al., 2013). In the 1970s, various compositions of synthetic $\mathrm{CaP}$, such as $\beta$-tricalcium phosphate ( $\beta$-TCP) or hydroxyapatite (HA), were proposed. Their importance and use have considerably increased over the past decades (Bohner, 2000). Their subtle differences in composition and structure may have a profound effect on their in vivo behaviour (Bohner, 2000). Besides differences in chemical properties, resorption and osseointegration, artificial bone graft might differ in case of bacterial colonisation and biofilm formation.

Surgical site infection is a recognised and often devastating complication in orthopaedic surgery ranging from $0.7-4.2 \%$ in elective orthopaedic surgery (Crockarell et al., 1998) to $30 \%$ following third degree open fractures (Ostermann et al., 1994). S. aureus and S. epidermidis are the main microorganisms responsible for $60-80 \%$ of these infections (Gristina, 1987; Trampuz and Zimmerli, 2006b). Despite antimicrobial prophylaxis in modern operating rooms, surgical site infections cannot be completely prevented (Trampuz and Zimmerli, 2006a), especially in the vicinity of a foreign body (Busscher et al., 2012). Bacteria are growing attached to the surface as biofilm (Costerton et al., 2005; Trampuz and Zimmerli, 2006b). The treatment and eradication of infections caused by biofilms is more difficult than of bacteria growing in free-living (planktonic) form (Busscher et al., 2012). The eradication of infection is often only possible by removal of the foreign body and long-term antimicrobial treatment (Ehrlich et al., 2005).

The "race to the surface" (Gristina, 1987) as a multistep process of initial bacterial adhesion and later biofilm formation is well established for metal implants (Gristina, 1987; Oga et al., 1988; Cordero et al., 1994; Vogely et al., 2000; Harris and Richards, 2006; Schlegel and Perren, 2006; Harris et al., 2007). In contrast, there 
are only limited data on biofilm formation on the surface of different $\mathrm{CaP}$ bone graft substitutes, mainly $\mathrm{HA}$ and tricalcium phosphate (Van Blitterswijk et al., 1986a; Van Blitterswijk et al., 1986b; Van Blitterswijk et al., 1986c; Jakubowski et al., 2008; Westas et al., 2014). Considering their increasing use in orthopaedic surgery, there might be more infected bone grafts in the future and differences in initial adhesion and biofilm formation might have a direct impact on clinical infection rates. Therefore, the aim of this study was to analyse the influence of material properties of 5 different synthetic $\mathrm{CaP}$ bone grafts on the initial adhesion and biofilm formation in an established in vitro setting (Clauss et al., 2010) using standard laboratory strains of $S$. aureus and $S$. epidermidis which are commonly causing surgical site bone infection.

\section{Material and Methods}

Four out of 5 examined CaP scaffolds used in the present study were produced using the so-called calcium phosphate emulsion method (Bohner, 2001; Kasten et al., 2003; Bohner et al., 2005). In brief, a powder mixture consisting of $80 \mathrm{~g}$ of $\alpha$-tricalcium phosphate $\left(\alpha-\mathrm{TCP} ; \alpha-\mathrm{Ca}_{3}\left(\mathrm{PO}_{4}\right)_{2}\right.$; produced in-house) and $20 \mathrm{~g}$ of tricalcium phosphate (Merck, Dietikon, Switzerland) was mixed with $100 \mathrm{~g}$ viscous paraffin oil (Merck) and $60 \mathrm{~mL}$ of $0.2 \mathrm{M} \mathrm{Na}_{2} \mathrm{HPO}_{4}$ aqueous solution containing $0.57 \mathrm{~g} / \mathrm{L}$ of polyethoxylated castor oil (Cremophor EL, BASF, Wädenswil, Switzerland), and $1 \%$ of $5.1 \mathrm{kDa}$ poly(acrylic acid) (Fluka, Buchs, Switzerland). After 2 min of mixing at $2000 \mathrm{rpm}$, the paste was poured into standing $30 \mathrm{~mL}$ syringes the tip of which had been pre-cut. Fourty-five minutes later, the samples were covered with $10 \mathrm{~mL}$ phosphate buffer (phosphatebuffered saline, PBS) (4.5 g/L NaCl, $1.79 \mathrm{~g} / \mathrm{L} \mathrm{KH}_{2} \mathrm{PO}_{4}$, $9.0 \mathrm{~g} / \mathrm{L} \mathrm{Na} \mathrm{HPO}_{4} \cdot 2 \mathrm{H}_{2} \mathrm{O}$ ), and incubated for one day at $60^{\circ} \mathrm{C}$. Then the samples were incubated in petroleum ether, dried and sintered at $1250{ }^{\circ} \mathrm{C}$. After drying, the samples were lathed to obtain the desired block dimensions. The last processing steps included a cleaning stage in ethanol and final calcination at $900{ }^{\circ} \mathrm{C}$ for $1 \mathrm{~h}$.

The samples obtained according to this procedure consisted of pure $\beta$-tricalcium phosphate $(\beta$-TCP; $\beta-\mathrm{Ca}_{3}\left(\mathrm{PO}_{4}\right)_{2}$, named here "chronOS" due to their similarity to the product sold by DePuy Synthes (West Chester, PA, USA). To obtain $\alpha$-TCP scaffolds, the $\beta$-TCP scaffolds (chronOS) were calcined at $1500{ }^{\circ} \mathrm{C}$ for $12 \mathrm{~h}$ and rapidly cooled down to room temperature. The conversion of $\alpha$-TCP scaffolds into dicalcium phosphate scaffolds (DCP; $\mathrm{CaHPO}_{4}$ ) occurred via a chemical reaction between $\alpha$-TCP scaffolds and a phosphoric acid solution (Galea et al., 2008).

For the synthesis of calcium-deficient hydroxyapatite $\left(\mathrm{CDHA} ; \mathrm{Ca}_{9}\left(\mathrm{PO}_{4}\right)_{5}\left(\mathrm{HPO}_{4}\right)(\mathrm{OH})\right)$, calcium phosphate emulsions were also used (Kasten et al., 2003). Compared to the synthesis of $\beta$-TCP scaffolds, polyacrylic acid was replaced by sodium citrate $(0.2 \mathrm{M}$ concentration $)$ and the fraction of emulsifier was reduced from 0.57 to $0.40 \mathrm{~g} / \mathrm{L}$. The incubation at $60{ }^{\circ} \mathrm{C}$ lasted $72 \mathrm{~h}$ instead of $24 \mathrm{~h}$ and the samples were cleaned with petroleum ether in a soxhlet device (VELP Scientifica, Usmate, Italy). The samples were not sintered.

The fifth CaP material (named here "cyclOS") was a $\beta$-TCP scaffold which was purchased at Mathys Ltd (Bettlach, Switzerland). According to the producer, these materials were obtained by pressing a mixture of tricalcium phosphate powder and polymer beads (125-625 $\mu \mathrm{m})$, followed by sintering at $1100{ }^{\circ} \mathrm{C}$.

\section{Physico-chemical characterisation}

Various physico-chemical characterisations were performed on all the investigated scaffolds: measurement of their weight, diameter, and height to determine their geometrical density and porosity, X-ray diffraction (XRD) to determine their crystalline composition, Nitrogen adsorption to determine their specific surface area (SSA) using the BET model, mercury porosimetry to determine their microstructure in the range between $7 \mathrm{~nm}$ and $100 \mu \mathrm{m}$ using the Washburn equation, scanning electron microscopy (SEM) and optical microscopy to look at their morphology and estimate the macropore size (pore size $>50-100 \mu \mathrm{m}$ ). More details are provided below.

The geometrical density was determined by dividing the weight by the apparent volume of the scaffolds. For XRD the scaffold was crushed, homogenised and packed in a cavity in an aluminium sample holder. XRD data were collected in reflective geometry on a Panalytical CubiX diffractometer (Panalytical, Eindhoven, The Netherlands) equipped with a graphite monochromator in the secondary beam. CuK $\alpha$ radiation and a step size of $0.02^{\circ}$ were used to measure from 4.01 to $59.99^{\circ} 2 \theta$. Quantitative phase analysis was done by Rietveld refinement with the computer program FullProf.2k (Version 5.00) (RodriguezCarvajal, 2001), using a previously determined instrument resolution function. Starting models for the quantified phases were taken from Dickens et al. (Dickens et al., 1974) for $\beta$-TCP, Mathew et al. (Mathew et al., 1977) for $\alpha$-TCP, Sudarsanan and Young (Sudarsanan and Young, 1969) for hydroxyapatite, Dickens et al. (Dickens et al., 1971) for DCP, and Curry and Jones (Curry and Jones, 1971) for dicalcium phosphate dihydrate (DCPD; $\mathrm{CaHPO}_{4} \cdot 2 \mathrm{H}_{2} \mathrm{O}$ ). The SSA was measured by nitrogen adsorption using the BET model (Gemini 2360, Micromeritics, Norcross, GA, USA). Four measurements were made per material. Total porosity and pore size distributions were evaluated with a mercury porosimeter up to $200 \mathrm{MPa}$ (Pascal 140/440, Thermo Fisher, Schwerte, Germany). Surface tension and contact angle of mercury were set to $0.480 \mathrm{~N} / \mathrm{m}$ and $140^{\circ}$, respectively. Samples were dried overnight at $130{ }^{\circ} \mathrm{C}$ in order to drive off any physisorbed water from the sample. Three different samples were measured to determine the standard deviation. For SEM, broken pieces of the scaffolds were placed on a sticky carbon tape, itself sticking on an aluminium sample holder. The particles were then sputtered with $\mathrm{C}$ and subsequently with $\mathrm{Au}$ to a total thickness of approximately $20 \mathrm{~nm}$. The samples were observed with an EVO MA25 microscope (Zeiss, Oberkochen, Germany). The macropore size of the samples was estimated by optical microscopy using a method previously described (Bohner et al., 2001). Briefly, photos of the surface of polished and cleaned scaffolds were taken (Leica (Wetzlar, Germany). 
MZ12 microscope, JVC KY-F70 digital camera, Image Access software). The average diameter of fifteen macropores was determined and an average macropore diameter, $\mathrm{D}_{\mathrm{e}}$, was calculated. The final macropore diameter, $D$, was calculated from $D_{e}$ using equation (1) (assuming that all the macropores are round and homogeneously distributed):

$$
D=\sqrt{\frac{3}{2}} D_{e}
$$

\section{Biofilm formation}

Two established biofilm forming staphylococcal strains were used (Clauss et al., 2010): S. aureus (ATCC 29213) is a gram-positive, coagulase-positive, methicillinsusceptible, biofilm-forming strain (Ceri et al., 2001). S. epidermidis RP62A (ATCC 35984) is a gram-positive, coagulase-negative, biofilm-forming strain (Merritt et al., 1998). The strains were stored at $-70{ }^{\circ} \mathrm{C}$ by using a cryovial bead preservation system (Microbank, Por. Lab Diagnostics, Richmond Hill, Ontario, Canada). For preparation of the inoculum, a single bead was freshly grown on sheep blood agar overnight. Bacterial inocula were prepared from discrete colonies resuspended in $1 \%$ PBS to a McFarland turbidity of 0.5 representing a bacterial concentration of $\sim 1.0 \times 10^{8}$ colony-forming units (cfu)/ $\mathrm{mL}$. The stock solution was diluted 1:1.000 for further experiments.

Biofilm formation was performed in (i) tryptic soy broth (TSB, Beton Dickinson AG, Basel Switzerland) and (ii) undiluted pooled human serum (serum, Millipore ${ }^{\mathrm{TM}}$ Temecula CA, United States) as recently published (Clauss et al., 2010). In brief, CaP bone grafts were inserted in $50 \mathrm{~mL}-$ Falcon tubes pre-filled with $2700 \mu \mathrm{L}$ of medium. To allow a homogeneous soaking of the porous materials over a $30 \mathrm{~min}$ period, samples were placed on top of the liquid surface (Stähli et al., 2010). At the end of the period, samples were completely submerged due to the additional water content in the pores (Clauss et al., 2013). In a final step, $300 \mu \mathrm{L}$ of diluted bacterial stock solution were added resulting in an initial bacterial concentration of $S$. aureus of $\sim 1.5 \times 10^{5} \mathrm{cfu} / \mathrm{mL}$, and for $S$. epidermidis $\sim 1.0 \times 10^{5}$ $\mathrm{cfu} / \mathrm{mL}$. Samples were incubated under static conditions at $37{ }^{\circ} \mathrm{C}$ with ambient air for either $3 \mathrm{~h}, 24 \mathrm{~h}$ or $72 \mathrm{~h}$.

Biofilm analysis was adapted from our recently published procedure (Clauss et al., 2010). Three steps were included: (i) washing procedure (all samples) followed by (ii) sonication (half of the samples) and (iii) a final microcalorimetric analysis (all samples).

(i) Washing procedure: After incubation, CaP scaffolds were transferred to a new $50 \mathrm{~mL}$-Falcon tube (prefilled with $5 \mathrm{~mL} 1 \%$ PBS) with a sterile forceps. They were washed 5 times with $5 \mathrm{~mL} 1 \%$ PBS to remove planktonic bacteria. For washing the PBS was poured in the Falcon tubes by placing a glass pipette on the wall of the Falcon tubes; afterwards the Falcon tubes were shaken cautiously by hand, and in a final step the PBS was sucked-off by placing a Pasteur pipette on top, to one side of the $\mathrm{CaP}$ scaffolds, to have a flush through the scaffold. Both the glass pipette and the Pasteur pipette were changed after processing one scaffold, to avoid contamination from one sample to another. Afterwards samples were split in two groups for further analysis: Group A was analysed by microcalorimetry alone and group B by sonication and microcalorimetry.

(ii) Sonication procedure (only group B): After washing, samples were transferred to new $50 \mathrm{~mL}-$ Falcon tubes containing $5 \mathrm{~mL} 1 \% \mathrm{PBS}$, gently shaken for $5 \mathrm{~s}$, sonicated at $40 \mathrm{kHz}$ for $5 \mathrm{~min}$ in a bath tub sonicator (BactoSonic, Bandelin, Germany) and shaken again for $5 \mathrm{~s}$. The dislodged biofilm (sonication fluid) was transferred to a $10 \mathrm{~mL}-$ Falcon tube and $\mathrm{CaP}$ bone grafts were stored for microcalorimetry (see below).

Sonication fluid was serially diluted in Eppendorf tubes and aliquots of $100 \mu \mathrm{L}$ were plated on sheep blood agar and incubated at $37^{\circ} \mathrm{C}$ aerobically for $24 \mathrm{~h}$. Bacterial counts were enumerated and expressed as cfu/sample. Plates were examined for variations in colony morphology (colour, size) and contaminations.

(iii) Microcalorimetry protocol (group $A$ and B): all microcalorimetry tests were performed using a 48-channel batch calorimeter (thermal activity monitor, model 3102 TAM III; TA Instruments, New Castle, DE, USA).

In more detail, biofilm-loaded CaP samples were transferred into sterile $4 \mathrm{~mL}$ calorimeter ampoules prefilled with $1 \mathrm{~mL}$ TSB, closed with a rubber cap and sealed by manual crimping. Ampoules were sequentially introduced into the microcalorimeter and remained for $15 \mathrm{~min}$ in the thermal equilibration position before they were lowered into the measurement position. Heat flow was measured continuously after the signal stability was achieved throughout an $18 \mathrm{~h}$ period and expressed as heat flow over time (in microwatts $[\mu \mathrm{W}]$ ). The calorimetric time to detection (TTD) was defined as the time from insertion of the ampoule into the calorimeter until the exponentially rising heat flow signal exceeded $50 \mu \mathrm{W}$ to distinguish microbial heat production from the thermal background. TTD indirectly quantifies the amount of bacteria with a shorter TTD representing a larger amount of bacteria. Data analysis was accomplished using the manufacturer's software (TAM Assistant; TA Instruments) and Prism 5.0 (GraphPad Software, La Jolla, CA).

\section{Statistical calculations}

Physico-chemical characterisation was done with at least three scaffolds of each material. Data are presented as mean and standard deviation (SD).

Biofilm experiments were performed in triplicates. To equalise variances in bacterial counts, data are presented as $\log _{10} \mathrm{cfu} /$ sample. For statistical analysis a one-way ANOVA with Bonferroni's multiple comparison test was performed using Prism 5.0 (GraphPad Software, La Jolla, CA). A $p$-value of $<0.05$ was considered to be significant.

\section{Results}

\section{Material characteristics}

Apart from the DCP samples, all scaffolds had a purity close to $100 \%$ (Table 1). The DCP scaffolds contained about $6 \%$ of remaining or unreacted $\alpha$-TCP. All samples contained large pores (macropores) with a diameter close 


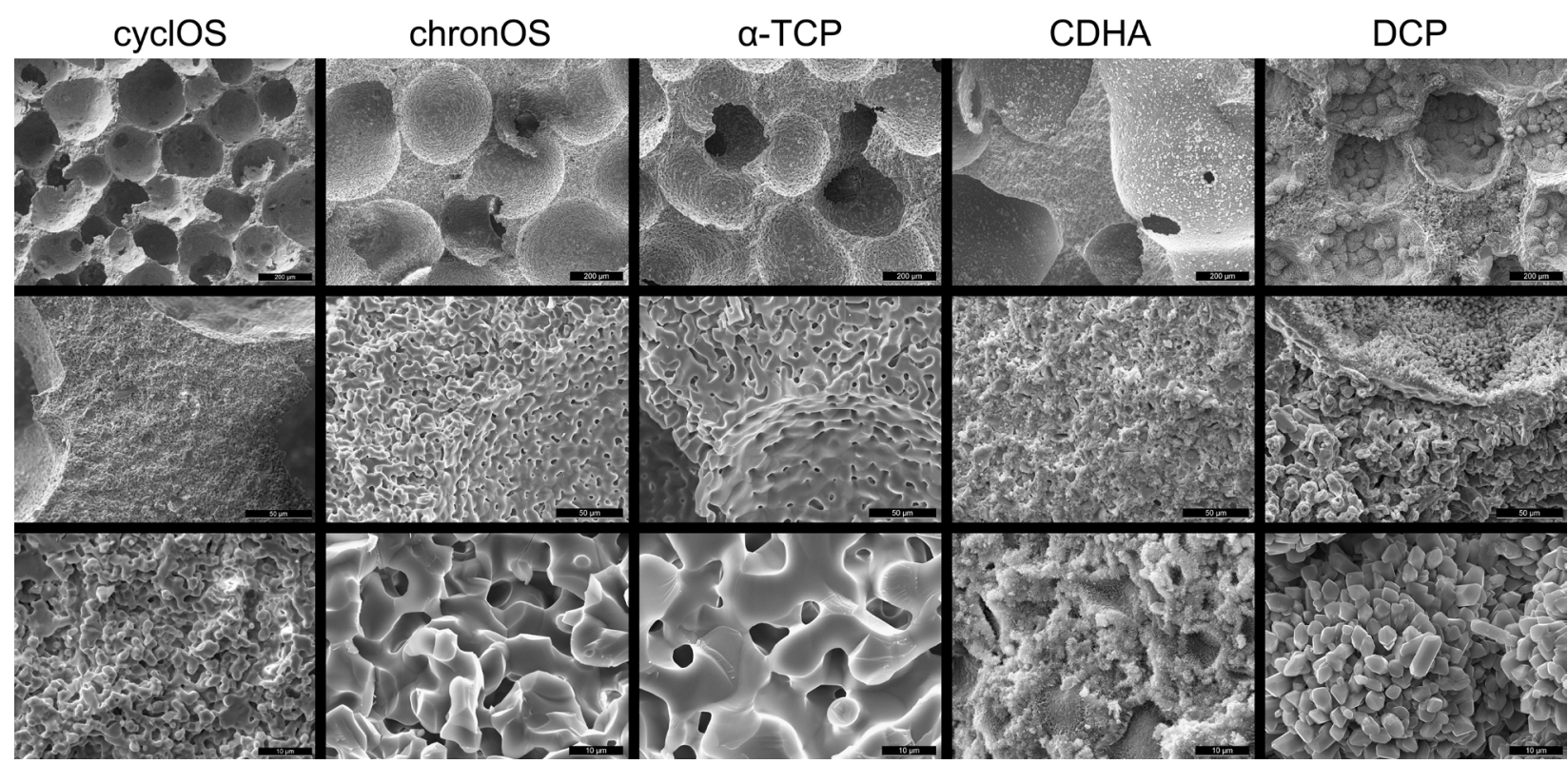

Fig. 1. SEM images of the 5 investigated CaP scaffold types. Three enlargements were used per material, from a small enlargement (images on top; scale bar: $200 \mu \mathrm{m}$ ) to a more detailed analysis of broken surfaces (images at the bottom; scale bar: $10 \mu \mathrm{m}$ ). The intermediate enlargements (middle images) have a scale bar of $50 \mu \mathrm{m}$.

Table 1. Summary of the physico-chemical properties of the samples used in the present study. Crystalline composition (Rietveld refinement analysis of the XRD data), specific surface area (SSA), macropore diameter, apparent density, porosity, median pore size (d50) and porosity accessible by bacteria $(>1.5 \mu \mathrm{m})$ in mean and standard deviation.

\begin{tabular}{|c|c|c|c|c|c|c|c|c|}
\hline & & $\begin{array}{c}\text { Specific } \\
\text { surface } \\
\text { area } \\
\end{array}$ & $\begin{array}{c}\text { Macropore } \\
\text { Diameter }\end{array}$ & App Density & Porosity & Porosity* & 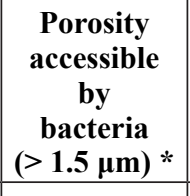 & $d_{50} *$ \\
\hline Material & Composition & {$\left[\mathrm{m}^{2} / \mathrm{g}\right]$} & {$[\mathrm{mm}]$} & {$\left[\mathrm{g} / \mathrm{cm}^{3}\right]$} & {$[\%]$} & {$[\%]$} & {$[\%]$} & {$[\mu \mathrm{m}]$} \\
\hline$\beta$-TCP (chronOS) & \begin{tabular}{|l} 
\\
\end{tabular} & $0.32 \pm 0.01$ & $0.39 \pm 0.09$ & $0.84 \pm 0.03$ & $72.6 \pm 1.0$ & $68 \pm 3$ & $59 \pm 3$ & $16 \pm 3$ \\
\hline$\beta$-TCP (cyclOS) & $>99 \%{ }^{2)}$ & $0.84 \pm 0.15$ & $0.26 \pm 0.07$ & $0.88 \pm 0.03$ & $71.1 \pm 1.0$ & $70 \pm 3$ & $59 \pm 3$ & $17 \pm 3$ \\
\hline$\alpha-$ TCP & $>99 \%$ & $0.16 \pm 0.10^{3)}$ & $0.41 \pm 0.09$ & $0.89 \pm 0.02$ & $68.9 \pm 0.7$ & $62 \pm 1$ & $61 \pm 1$ & $51 \pm 4$ \\
\hline DCP & $\begin{array}{l}93 \% \text { DCP, } \\
6 \% \alpha-T C P, \\
1 \% \text { DCPD }\end{array}$ & $4.04 \pm 0.35$ & $0.37 \pm 0.08$ & $1.17 \pm 0.04$ & $60.0 \pm 1.4$ & $46 \pm 2$ & $37 \pm 2$ & $27 \pm 7$ \\
\hline CDHA & $\begin{array}{l}98 \% \text { HA, } \\
2 \% \text { DCP }\end{array}$ & $43.6 \pm 0.4$ & $0.53 \pm 0.13$ & $0.53 \pm 0.01$ & $82.0 \pm 0.3$ & $69 \pm 4$ & $27 \pm 9$ & $\begin{array}{c}0.23 \pm \\
0.18\end{array}$ \\
\hline
\end{tabular}

* Determined by mercury porosimetry

${ }^{1)}$ Crystallite size: $163 \pm 34 \mathrm{~nm}( \pm 1$ St Dev $)$

${ }^{2)}$ Crystallite size: $103 \pm 12 \mathrm{~nm}( \pm 1 \mathrm{St}$ Dev $)$

${ }^{3)}$ This value is at the lower range of what the instrument can measure

Fig. 2. Representative curves showing the normalised pore size distributions of the 5 investigated CaP scaffold types. The curves represent the fraction of the pores smaller than a given value. The vertical line corresponds to the approximate size of bacteria.

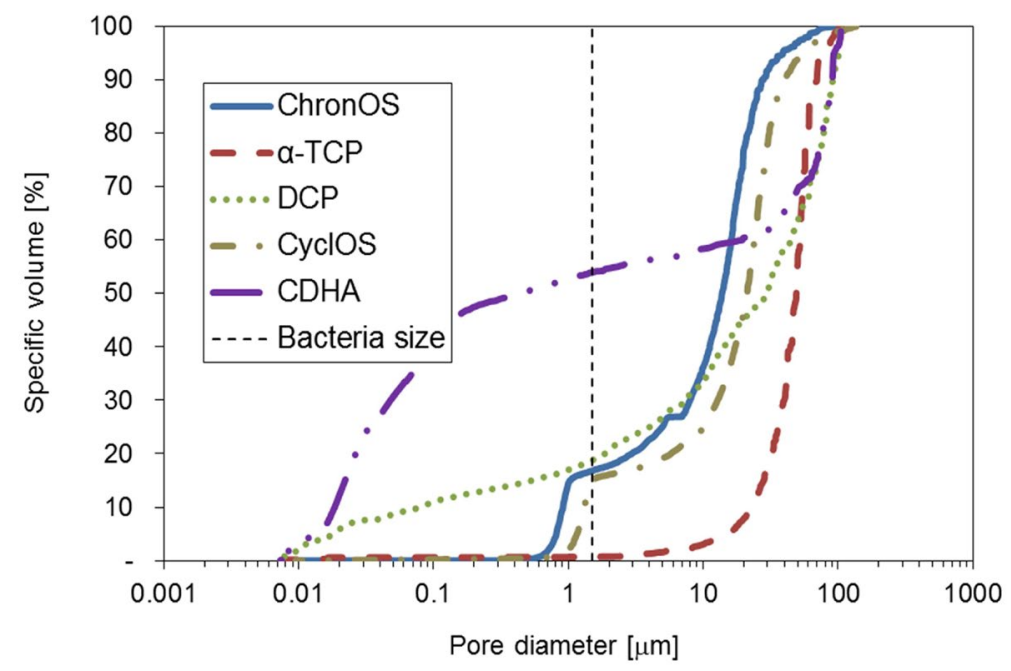


a)
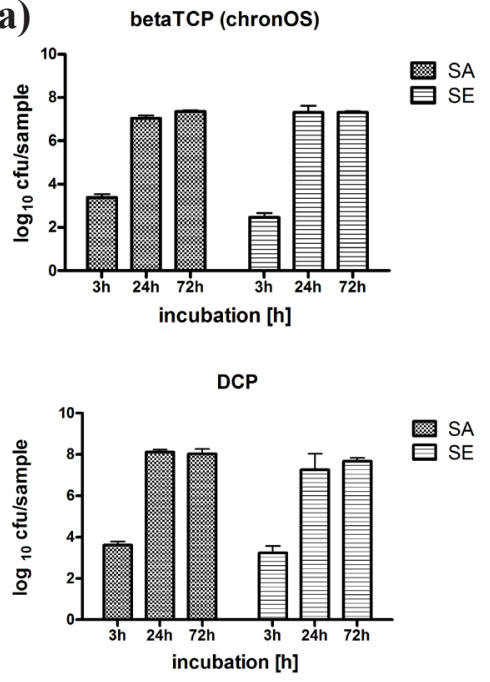

b) betaTCP (chronos)

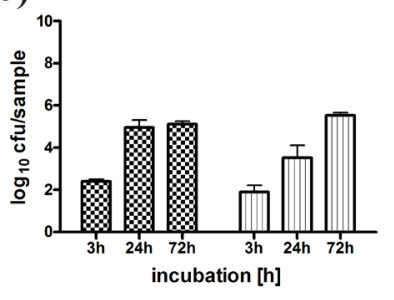

DCP

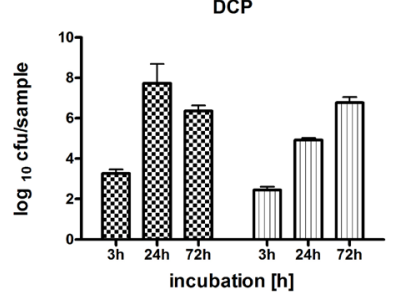

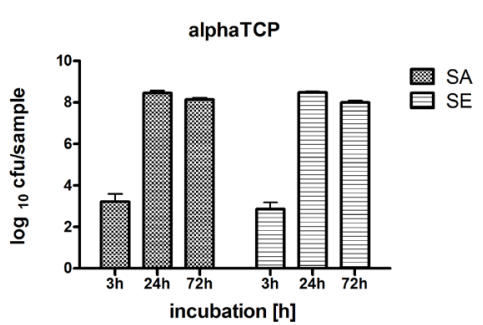
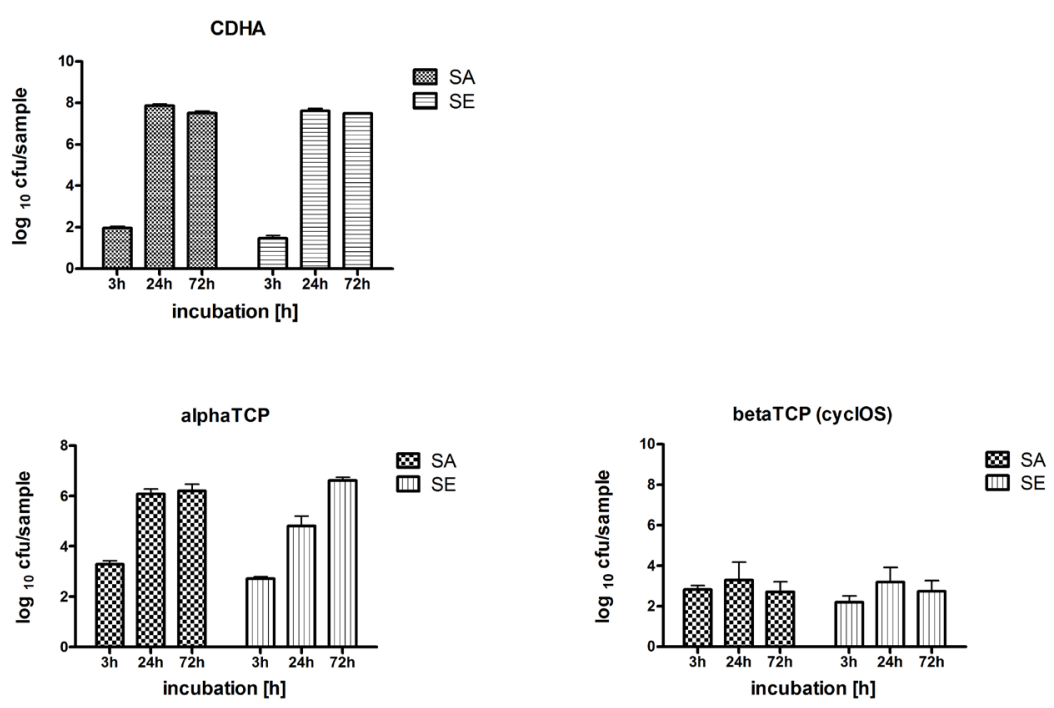

Fig. 3. The cfu count in sonication fluid of scaffolds incubated in (a) TSB and (b) serum (SA S. aureus, SE $S$. epidermidis). Data presented as mean $\pm \mathrm{SD}$.

to $0.2-0.6 \mathrm{~mm}$ and smaller pores, either in the $\mathrm{nm}(e . g$, for CHDA and DCP) or in the low $\mu \mathrm{m}$ range $(1-10 \mu \mathrm{m})$ (Table 1, Fig. 1).

$\alpha$-TCP and DCP scaffolds were produced from $\beta$-TCP scaffolds (chronOS), so their macropore size distribution and morphology were similar (Fig. 1; first row). However, the macropores of DCP samples were partly filled with small DCP protuberances, which led to a $10 \%$ lower porosity and $5-10 \%$ decrease in macropore size compared to $\beta$-TCP and $\alpha$-TCP scaffolds (Table 1 ). The difference of microstructure seen on the SEM photos between the various scaffolds was reflected by large variations of SSA values. Indeed, the SSA values of the scaffolds varied over a very wide range, starting from $0.16 \pm 0.10 \mathrm{~m}^{2} / \mathrm{g}$ for $\alpha$-TCP scaffolds up to $43.6 \pm 0.4 \mathrm{~m}^{2} / \mathrm{g}$ for CDHA scaffolds.

SEM images also revealed that CDHA samples had the largest macropore size $(0.53 \pm 0.13 \mathrm{~mm})$, whereas cyclOS samples had the smallest macropore size $(0.26 \pm 0.07 \mathrm{~mm})$. These observations were supported by the macropore size estimated from polished scaffold surfaces (Table 1). However, changes in macropore size remained small.
Contrarily, large differences in micropore size were observed by SEM. Qualitatively, the mean pore size as determined by $\mathrm{Hg}$ porosimetry decreased in the order: $\alpha$-TCP $>$ chronOS $>$ DCP $>$ cyclOS $>$ CDHA (Table 1).

Microstructure in terms of pore size distribution was further studied by $\mathrm{Hg}$ porosimetry to evaluate the possible bacteria invasion into the structure (Fig 2). Pore size distributions were normalised according to their volume in order to show the differences between scaffolds. According to these results, all materials but $\alpha$-TCP had pores small enough to partly prevent bacterial invasion (estimated size of the two bacterial strains: $1.5 \mu \mathrm{m}$ ). Whereas the porosity fraction, not accessible to bacteria, was close to $80-87 \%$ for chronOS, cyclOS and DCP, this value dropped to $39 \%$ for CDHA scaffolds (= $27 \% / 69 \%$ ).

The porosities determined by $\mathrm{Hg}$ porosimetry were 1 to $14 \%$ smaller than the values obtained via the determination of the geometrical density (Table 1). Whereas the differences were small for chronOS and cyclOS (4\% and $1 \%)$, much larger differences were observed for DCP $(14 \%)$ and CDHA (13\%). 


\section{$\beta$-TCP (chronOS)}

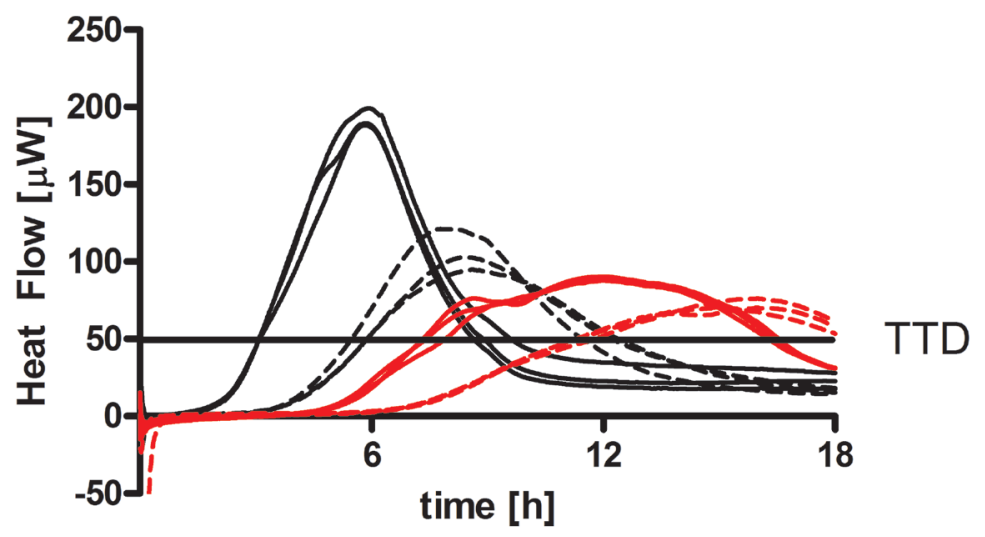

\section{Biofilm formation}

Both test strains formed a biofilm on all test materials, as confirmed by quantitative culture after washing and sonication of the CaP scaffolds. The amount of biofilm removed from the scaffolds showed low variation within a triplicate and was comparable for 4 of the 5 tested materials, namely $\alpha$-TCP, chronOS, CDHA and DCP but different for cyclOS (Fig. 3a,b).

For $\alpha$-TCP, chronOS, CDHA and DCP incubated with $S$. aureus in TSB, differences between $3 \mathrm{~h}$ and $24 \mathrm{~h}$ $(p<0.001), 3 \mathrm{~h}$ and $24 \mathrm{~h}(p<0.001)$ and $24 \mathrm{~h}$ and $72 \mathrm{~h}$ $(p>0.05)$ were comparable. The differences were the same when these 4 materials were incubated with $S$. aureus in serum, and when incubated with $S$. epidermidis in TSB (Fig. 3).

For cyclOS incubated with $S$. aureus in TSB, differences were less marked between $3 \mathrm{~h}$ and $24 \mathrm{~h}(p<0.01), 3 \mathrm{~h}$ and $24 \mathrm{~h}(p<0.05)$ and $24 \mathrm{~h}$ and $72 \mathrm{~h}(p>0.05)$. When cyclOS was incubated in serum there were no significant differences $(p>0.05)$ between the 3 time points (Fig. 3a).

When the 5 materials were incubated with $S$. epidermidis in serum, again no significant differences $(p>0.05)$ were found between the 3 time points for cyclOS, but a continuous and highly significant increase was noticed between $3 \mathrm{~h}$ and $24 \mathrm{~h}$ for $\alpha$-TCP $(p<0.001)$, chronOS $(p<0.01)$, CDHA $(p<0.001)$, and DCP $(p<0.001)$, and between $24 \mathrm{~h}$ and $72 \mathrm{~h}$ for $\alpha$-TCP $(p<0.001)$, chronOS $(p<0.001)$, and DCP $(p<0.001)$ (Fig. 3b).

The qualitative analysis of the biofilm showed a homogenous size of CFU in the sonication fluid for all samples without contaminations on the plates.

The triplicates in microcalorimetric measurements showed a high uniformity of the shape of the curves (indicating no gross contamination on the scaffolds) with low variations in TTD, independent from the strain, growth medium, and length of incubation (Fig. 4). When these findings are combined with the qualitative analysis of the sonication fluid, contaminations on the samples can be excluded.

The lowest number of bacteria (longest TTD) was found on the surface of the CDHA scaffolds ( $p<0.001$ S. aureus and S. epidermidis) after $3 \mathrm{~h}$ incubation in TSB (Fig. 5a). The differences decreased after $24 \mathrm{~h}$ incubation $(p>0.05$
S.aureus, $p<0.05$ S. epidermidis) and disappeared after $72 \mathrm{~h}$ incubation $(p>0.05)$. When incubated in serum, there was significantly less biofilm on the surface of the CDHA and the cyclOS scaffolds as compared to the three other samples after $3 \mathrm{~h}$ incubation $(p<0.001)$. After $24 \mathrm{~h}$ and $72 \mathrm{~h}$ incubation cyclOS showed the lowest amount of biofilm (Fig. 5).

When the samples from group A (washing) and group B (washing and sonication) were compared less biofilm (longer TTD) was detected on the surface of all samples, but no change in the relative differences between the materials, time-points, and media (Fig. 5). All materials showed less biofilm (longer TTD) at corresponding time points when incubated in serum as compared to TSB (Fig. $5)$.

The amount of biofilm detected by microcalorimetry (TTD) for group A (washing) and B (washing and sonication) correlated well with the cfu counts after sonication.

\section{Discussion}

Numerous studies have been devoted to the quest of an ideal bone scaffold design (pore size, interconnectivity, shape, stability) without giving a clear answer (Bohner et al., 2011). Furthermore, depending on the clinical application, these specifications might vary. Design modifications may not only change bony ingrowth and substitution with time (Bohner et al., 2011) but also influence bacterial adhesion and the related risk of infection (Clauss et al., 2013) because they use the same adhesive mechanisms (Busscher et al., 2012). From a clinical perspective, initial bacterial colonisation, competing with tissue cell integration, better known as the "race to the surface" (Gristina, 1987), is the most important step as it preludes biomaterial associated infection (Busscher et al., 2012).

Extensive research has been performed to determine the propensity of medical devices to sustain biofilm formation by staphylococci (Busscher et al., 2012; Clauss et al., 2010; Harris and Richards, 2006). It has been shown, that various physico-chemical factors influence in vitro biofilm formation on a surface (Harris et al., 2007; Jakubowski 
a) S. aureus (TSB)

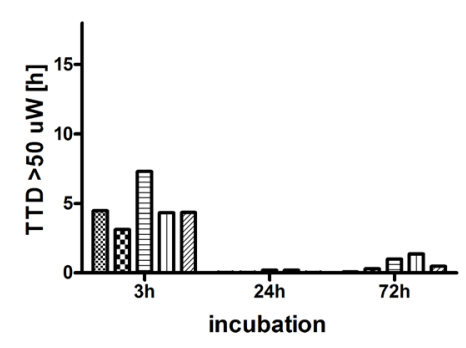

S. epidermidis (TSB)

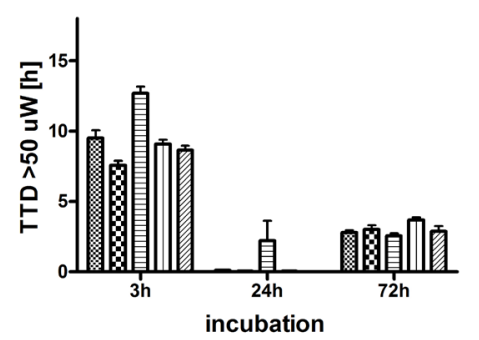

b)

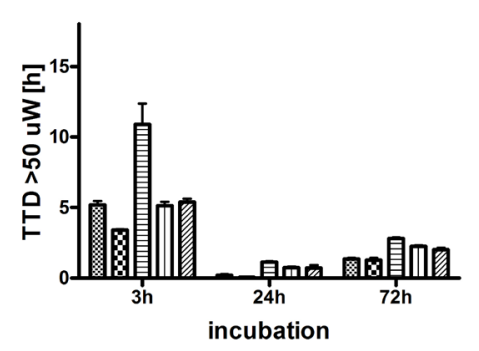

S. epidermidis (TSB)

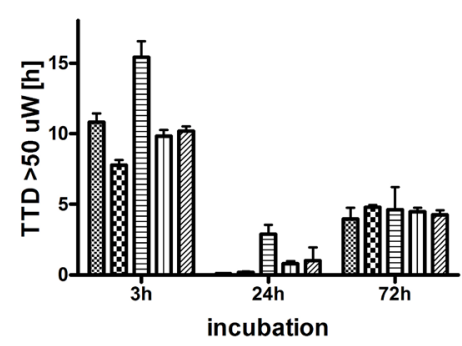

S. aureus (Serum)

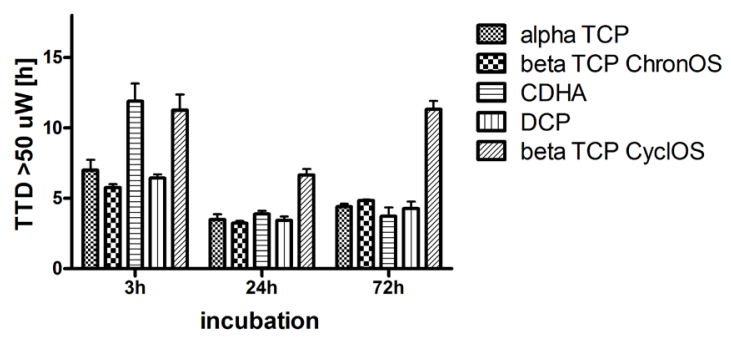

S. epidermidis (Serum)

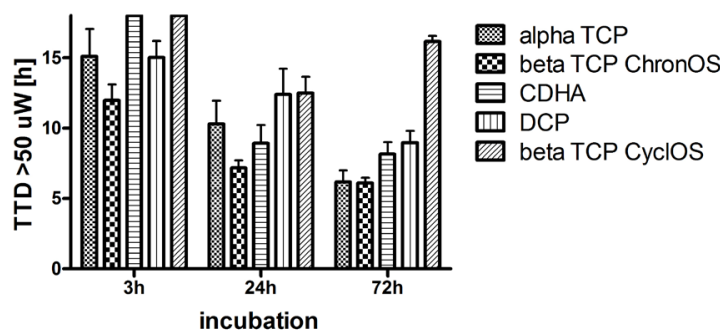

S. aureus (Serum)

alpha TCP

$\otimes$ beta TCP ChronOs

回 CDHA

孟 DCP

beta TCP CyclOs

$\mathrm{B}$ beta TCP ChronOs

O CDHA

四 DCP

beta TCP CyclOS

Fig. 5. Results from microcalorimetry. (a) washing procedure (group A), (b) washing and sonication (group B). Data presented as mean $\pm \mathrm{SD}$.

et al., 2008; MacKintosh et al., 2006; Oga et al., 1988; Patel et al., 2003; Patel et al., 2007). There is only limited information about staphylococcal biofilm formation on the surface of CaP bone grafts investigating $S$. aureus biofilm formation on either HA (Van Blitterswijk et al., 1986a; Van Blitterswijk et al., 1986b) or $\beta$-TCP (Van Blitterswijk et $a l ., 1986 \mathrm{c})$ in the middle ear of rats.

The aim of this study was to analyse the influence of physico-chemical and structural variations of $\mathrm{CaP}$ bone grafts on staphylococcal biofilm formation under standardised in vitro conditions.

Several CaP materials were selected based on their clinical and scientific relevance. Nowadays, $\beta$-TCP is perhaps the most commonly used $\mathrm{CaP}$ bone graft substitute (Bohner, 2010). Therefore, two $\beta$-TCP scaffolds used clinically were considered. These two materials present very similar pore architectures. In both cases, the pores are spherical, the porosity is close to $70 \%$, and the structure is highly microporous (Figs. 1 and 2). The specific surface area is larger, whereas the macropores are slightly smaller and less interconnected for cyclOS compared to chronOS. CDHA is generally not used as scaffold due to its more complex manufacturing process (Steffen et al., 2001; Kasten et al., 2003), but since it is the end product of the setting reaction of many calcium phosphate cements, it is a relevant material. Also, CDHA is a very interesting material to analyse considering the importance of surfaces for bacterial biofilms. Indeed, its specific surface area is several orders of magnitude larger than that of $\beta$-TCP and $\alpha$-TCP scaffolds (Table 1 ). Whereas CDHA and $\beta$-TCP 
solubilities are very similar, the two last materials, i.e., DCP and $\alpha$-TCP, have a much higher solubility (Chow, 1991), which may affect their bacterial reaction. Furthermore, DCP is considered to be one of the most promising bone graft substitute materials (Habibovic et al., 2008; Bohner, 2010).

All scaffolds are composed of pores large enough and interconnected enough to allow the invasion of bacteria (Ø 0.5-1.5 $\mu \mathrm{m})$ into the structure. However, differences can be found between scaffolds: whereas only $39 \%$ of CDHA porosity can be invaded by $1.5 \mu \mathrm{m}$ spheres, this value increases to $80-87 \%$ for DCP, chronOS and cyclOS, and reaches $100 \%$ for $\alpha$-TCP.

The two scaffold types with the lowest porosity accessible by bacteria (CDHA and DCP) are also the scaffolds with the highest SSA values and presenting the largest differences between the porosity inferred from the geometrical density and from $\mathrm{Hg}$ porosimetry measurements. These results suggest that CDHA and DCP scaffolds are partly crushed during $\mathrm{Hg}$ impregnation, hence leading to an overestimation of the total porosity, and an error in the porosity fraction smaller than $1.5 \mu \mathrm{m}$. Indeed, the scaffolds used in the present study have a compressive strength inferior to $10 \mathrm{MPa}$ (particularly CDHA), which is the pressure required to invade $0.15 \mu \mathrm{m}$ pores. At this pressure (or this pore size), only $\approx 50 \%$ of the CDHA pores are invaded by $\mathrm{Hg}$ (and $\approx 90 \%$ of the DCP pores).

Choosing the appropriate strain is one of the most crucial steps when biofilm formation is investigated. Clinical isolates are not well characterised and results might be difficult to compare to the literature. We therefore used standard (ATCC) strains which are known to produce reproducible amounts of biofilm already after $3 \mathrm{~h}$ for $S$. aureus (Ceri et al., 1999) and S. epidermidis (Polonio et al., 2001; Chaw et al., 2005; Qin et al., 2007), at the surface of various bone grafts (Clauss et al., 2010; Clauss et al., 2013).

Two different growth media (TSB and human serum) were chosen because it has been shown that growth media have a considerable influence on biofilm formation, as they change the initial bacterial adhesion on the surface (Barton et al., 1996; Patel et al., 2007). TSB was frequently used in previous studies (Clauss et al., 2010; Clauss et al., 2013), and additionally we used normal undiluted pooled human serum which was not heat-inactivated by the manufacturer. The presence of bacterial biofilms grown in serum proves that the two staphylococcal strains tested were able to survive and proliferate (more bacteria after $24 \mathrm{~h}$ and $72 \mathrm{~h}$ compared to $3 \mathrm{~h}$ of incubation). Compared to the dislodged biofilms that had been cultured in TSB (Fig. $3 \mathrm{a}$ ), the biofilms grown in serum were slightly smaller (i.e., lower cfu counts obtained). This could be explained by the fact that the TSB is a very nutrient-rich growth medium in comparison to serum. We believe that in vitro experiments performed in serum better represent the clinical setting, where the bacteria are present in a more challenging and harsh environment, compared to the nutrient-rich TSB.

The goal of this study was to investigate the effect of different physico-chemical material characteristics on staphylococcal biofilm formation, and not to compare different growth media. Therefore, we did not emphasise the difference in growth between the two culture media. An interesting observation was that less biofilm was found on the cyclOS scaffolds both when TSB and serum were used, which proved that the smaller amount of biofilm found on this particular material was not due to interaction between the growth media (TSB or serum) and the material.

Various methods for quantitative/qualitative evaluation of biofilm formation, like "live-dead staining", confocal laser scanning microscopy (CLSM) or SEM have been described. All methods except calorimetry need a special pre-treatment, such as staining (live-dead staining, CLSM) or carbon-sputtering (SEM), which interfere with further biofilm investigation (Clauss et al., 2010). The surface that can be monitored by other methods is restricted to small areas while microcalorimetry monitors the whole device (Clauss et al., 2010). For microcalorimetric monitoring of biofilm formation it is essential to remove planktonic bacteria from the scaffolds, and washing might be critical with porous materials such as $\mathrm{CaP}$ bone grafts. Planktonic bacteria might remain in the pores, resulting in an overestimation of the true amount of biofilm. To minimise this effect we modified our recently published washing protocol (Clauss et al., 2010) for removal of planktonic bacteria. Uniformly, all samples were washed five times placing the suction device directly on top, and to one side, of the sample producing a flush through the scaffolds. We cannot quantify the amount of remaining planktonic bacteria but variations in cfu counts and TTD within a triplicate have been low, thus systematic error should be low and comparable on all scaffolds.

Several material parameters are known to modify the rate of infection in vitro. For example, porous materials have a higher rate of infection than dense materials (Merritt et al., 1998; Harris et al., 2007; Clauss et al., 2010). Rough materials are also more prone to infection (Lange et al., 2002; Meredith et al., 2005). The investigated $\mathrm{CaP}$ bone grafts were porous, with a microscopically and macroscopically rough surface. The materials presented obvious but moderate differences in porosity and roughness, as revealed by SEM, Hg porosimetry, and nitrogen adsorption. Biofilm formation on the surface of the $\mathrm{CaP}$ samples by means of sonication and microcalorimetry was comparable for $\alpha$-TCP, chronOS, CDHA and DCP, but much lower for cyclOS. This is peculiar because this calcium phosphate had an intermediate porosity (Table 1), mean pore size, specific surface area, and porosity accessible to bacteria. Therefore, it is unclear why cyclOS would be less prone to biofilm formation than the other materials.

Hydrophobicity has been shown to be an important factor for initial bacterial adhesion and E. coli biofilm formation on the surface of HA and $\beta$-TCP (Jakubowski et al., 2008).

In the past, Staehli et al. had shown that cyclOS samples were more difficult to impregnate by a fluid than chronOS (Stähli et al., 2010), what might result in a higher volume of air in the cyclOS samples reducing the surface available for biofilm formation. They established an impregnation test setup and assessed the effect of various synthesis parameters, such as sintering temperature, composition, macroporosity and macropore size on the impregnation 
properties of porous $\mathrm{CaP}$ scaffolds dipped in water. Among those parameters, the macropore size had by far the largest effect; generally, the bigger the macropore size, the lower the saturation level. The results also showed that impregnation was less complete when the samples were fully dipped in water than when they were only partially dipped, owing to the requirement for the system to create air bubbles under water. We were not able to modify pore size of the samples as this was one of our major issues in the present study, but we placed the scaffolds on top of the surface of the liquid allowing them to submerge within $30 \mathrm{~min}$, wetting just as much surface as possible. One would also expect that the effect of entrapped air should reduce with time, thus the influence on the results should become smaller from the $3 \mathrm{~h}$ to $24 \mathrm{~h}$ and $72 \mathrm{~h}$ incubation. As differences in biofilm formation became more obvious by longer incubation intervals, differences in impregnation can most likely not explain the observed differences in biofilm formation. Besides hydrophobicity, bacterial adhesion can also be influenced by the charge of the surface, i.e., negatively charged bacteria adhere better to a positively charged surface ( $\mathrm{Li}$ and Logan, 2004). We did not investigate surface charge, thus we cannot exclude that surface charge influenced our results.

\section{Conclusion}

All investigated $\mathrm{CaP}$ bone grafts showed significant amounts of biofilm on the surface already after $24 \mathrm{~h}$. CyclOS had the lowest biofilm formation, but this difference cannot be explained rationally based on the physico-chemical characterisations such as pore size distribution, porosity, specific surface area. Our results suggest that biofilm formation is not influenced by a single physico-chemical parameter alone, but is a multi-step process influenced by several factors in parallel. Further studies are needed to decipher the whole cascade. Infections on the surface of medical devices are mainly acquired perioperative, thus a high resistance against initial bacterial adhesion and biofilm formation is favourable to reducing infection rates with medical devices. Transfer from in vitro data to the clinical situation is difficult. As there might be various reasons for reduced biofilm formation on cyclOS scaffolds, compared with the four other $\mathrm{CaP}$ bone grafts, we believe that advocating cyclOs in clinical situations with a high risk of infection such as e.g., open fractures, cannot clearly be supported based on our data.

\section{Acknowledgements}

This study was supported by research grants from the RMS Foundation; Bettlach, Switzerland (E09_0001), the Swiss Society of Orthopaedics and Traumatology (SGOT/SSOT) and 3R Foundation (S124-10). S. epidermidis RP62A (ATCC 35984) was kindly provided by Prof. P. Vaudaux from the Department of Infectious Disease, University Hospital, Geneva, Switzerland. At the RMS Foundation we want to thank S. Grünefelder and P. Brotschi for their help producing the scaffolds, W. Hirsinger for his help with the
SEM studies and L. Galea for the BET and XRD analysis. Furthermore we have to thank S. Gersbach (Kantonsspital Baselland Liestal) for her help with data management and analysis.

\section{References}

Barton AJ, Sagers RD, Pitt WG (1996) Bacterial adhesion to orthopedic implant polymers. J Biomed Mater Res 30: 403-410.

Bohner M (2000) Calcium orthophosphates in medicine: from ceramics to calcium phosphate cements. Injury 31 Suppl 4: 37-47.

Bohner M (2001) Calcium phosphate emulsions: possible applications. Key Eng Mater 192-195: 765-768.

Bohner M (2010) Resorbable biomaterials as bone graft substitutes. Mat Today 13: 24-30.

Bohner M, Van Lenthe GH, Grünenfelder S, Hirsiger W, Evison R, Müller R (2005) Synthesis and characterization of porous beta-tricalcium phosphate blocks. Biomaterials 26: 6099 .

Bohner M, Loosli Y, Baroud G, Lacroix D (2011) Commentary: Deciphering the link between architecture and biological response of a bone graft substitute. Acta Biomater 7: 478-484.

Busscher HJ, van der Mei HC, Subbiahdoss G, Jutte PC, van den Dungen JJ, Zaat SA, Schultz MJ, Grainger DW (2012) Biomaterial-associated infection: locating the finish line in the race for the surface. Sci Transl Med 4: 153 rv110.

Ceri H, Olson M, Morck D, Storey D, Read R, Buret A, Olson B (2001)The MBEC assay system: Multiple equivalent biofilms for antibiotic and biocide susceptibility testing. In: Methods Enzymol 337: 377-385.

Ceri H, Olson ME, Stremick C, Read RR, Morck D, Buret A (1999) The Calgary Biofilm Device: New technology for rapid determination of antibiotic susceptibilities of bacterial biofilms. J Clin Microbiol 37: 1771-1776.

Chaw KC, Manimaran M, Tay FEH (2005) Role of silver ions in destabilization of intermolecular adhesion forces measured by atomic force microscopy in Staphylococcus epidermidis biofilms. Antimicrob Agents Chemother 49: 4853-4859.

Chow LC (1991) Development of self-setting calcium phosphate cements. Japan Ceram Soc 99: 954-964.

Clauss M, Trampuz A, Borens O, Bohner M, Ilchmann $\mathrm{T}$ (2010) Biofilm formation on bone grafts and bone graft substitutes: comparison of different materials by a standard in vitro test and microcalorimetry. Acta Biomater 6: 3791 3797.

Clauss M, Tafin UF, Bizzini A, Trampuz A, Ilchmann T (2013) Biofilm formation by staphylococci on fresh, fresh-frozen and processed human and bovine bone grafts. Eur Cell Mater 25: 159-166.

Cordero J, Munuera L, Folgueira MD (1994) Influence of metal implants on infection. An experimental study in rabbits. J Bone Joint Surg Br 76: 717-720.

Costerton JW, Montanaro L, Arciola CR (2005) Biofilm in implant infections: its production and regulation. Int $\mathrm{J}$ Artif Organs 28: 1062-1068. 
Crockarell JR, Hanssen AD, Osmon DR, Morrey BF (1998) Treatment of infection with debridement and retention of the components following hip arthroplasty. J Bone Joint Surg Am 80: 1306-1313.

Curry NA, Jones DW (1971) Crystal structure of brushite, calcium hydrogen orthophosphate dihydrate: a neutron diffraction investigation. J Chem Soc (A) Inorg Phys Theor 1971: 3725-3729.

Delloye C, Cornu O, Druez V, Barbier O (2007) Bone allografts: What they can offer and what they cannot. J Bone Joint Surg Br 89: 574-579.

Dickens B, Bowen JS, Brown BE (1971) A refinement of the crystal structure of CaHPO4 (synthetic monetite). Acta Cryst B28: 797-806.

Dickens B, Schroeder LW, Brown BE (1974) Crystallographic studies of the role of $\mathrm{Mg}$ as a stabilizing impurity in $\beta-\mathrm{Ca}_{3}\left(\mathrm{PO}_{4}\right)_{2}$. I. The crystal structure of pure $\beta-\mathrm{Ca}_{3}\left(\mathrm{PO}_{4}\right)_{2}$. J Solid State Chem 10: 232-248.

Ehrlich GD, Stoodley P, Kathju S, Zhao Y, McLeod BR, Balaban N, Hu FZ, Sotereanos NG, Costerton JW, Stewart PS, Post JC, Lin Q (2005) Engineering approaches for the detection and control of orthopaedic biofilm infections. Clin Orthop Relat Res 437: 59-66.

Galea LG, Bohner M, Lemaitre J, Kohler T, Muller R (2008) Bone substitute: transforming beta-tricalcium phosphate porous scaffolds into monetite. Biomaterials 29: 3400-3407.

Gristina AG (1987) Biomaterial-centered infection: Microbial adhesion versus tissue integration. Science 237: 1588-1595.

Habibovic P, Gbureck U, Doillon CJ, Bassett DC, van Blitterswijk CA, Barralet JE (2008) Osteoconduction and osteoinduction of low-temperature 3D printed bioceramic implants. Biomaterials 29: 944-953.

Harris LG, Richards RG (2006) Staphylococci and implant surfaces: a review. Injury 37 Suppl 2: S3-14.

Harris LG, Meredith DO, Eschbach L, Richards RG (2007) Staphylococcus aureus adhesion to standard microrough and electropolished implant materials. J Mater Sci: Mater Med 18: 1151-1156.

Jakubowski W, lósarczyk A, Paszkiewicz Z, Szymanski W, Walkowiak B (2008) Bacterial colonisation of bioceramic surfaces. Adv Appl Ceram 107: 217-222.

Kappe T, Cakir B, Mattes T, Reichel H, Flören M (2010) Infections after bone allograft surgery: a prospective study by a hospital bone bank using frozen femoral heads from living donors. Cell Tissue Banking 11: 253-259.

Kasten P, Luginbuhl R, van Griensven M, Barkhausen T, Krettek C, Bohner M, Bosch U (2003) Comparison of human bone marrow stromal cells seeded on calciumdeficient hydroxyapatite, beta-tricalcium phosphate and demineralized bone matrix. Biomaterials 24: 2593-2603.

Ketonis C, Barr S, Adams CS, Hickok NJ, Parvizi J (2010) Bacterial colonization of bone allografts: establishment and effects of antibiotics. Clin Orthop Relat Res 468: 2113-2121.

Lange R, Luthen F, Beck U, Rychly J, Baumann A, Nebe B (2002) Cell-extracellular matrix interaction and physico-chemical characteristics of titanium surfaces depend on the roughness of the material. Biomol Eng 19: 255-261.
Li B, Logan BE (2004) Bacterial adhesion to glass and metal-oxide surfaces. Colloids Surf B Biointerfaces 36: 81-90.

MacKintosh EE, Patel JD, Marchant RE, Anderson JM (2006) Effects of biomaterial surface chemistry on the adhesion and biofilm formation of Staphylococcus epidermidis in vitro. J Biomed Mater Res A 78: 836-842.

Mathew M, Schroeder LW, Dickens B, Brown WE (1977) The crystal structure of a-Ca $\left(\mathrm{PO}_{4}\right)_{2}$. Acta Cryst B33: 1325-1333.

Meredith DO, Eschbach L, Wood MA, Riehle MO, Curtis AS, Richards RG (2005) Human fibroblast reactions to standard and electropolished titanium and Ti-6Al-7Nb, and electropolished stainless steel. J Biomed Mater Res A 75: 541-555.

Merritt K, Gaind A, Anderson JM (1998) Detection of bacterial adherence on biomedical polymers. J Biomed Mater Res 39: 415-422.

Oga M, Sugioka Y, Hobgood CD, Gristina AG, Myrvik QN (1988) Surgical biomaterials and differential colonization by Staphylococcus epidermidis. Biomaterials 9: $285-289$.

Ostermann PA, Henry SL, Seligson D (1994) Timing of wound closure in severe compound fractures. Orthopedics 17: 397-399.

Patel JD, Ebert M, Stokes K, Ward R, Anderson JM (2003) Inhibition of bacterial and leukocyte adhesion under shear stress conditions by material surface chemistry. J Biomater Sci Polym Ed 14: 279-295.

Patel JD, Ebert M, Ward R, Anderson JM (2007) S. epidermidis biofilm formation: Effects of biomaterial surface chemistry and serum proteins. J Biomed Mater Res A 80: 742-751.

Polonio RE, Mermel LA, Paquette GE, Sperry JF (2001) Eradication of biofilm-forming Staphylococcus epidermidis (RP62A) by a combination of sodium salicylate and vancomycin. Antimicrob Agents Chemother 45: 3262-3266.

Qin Z, Yang X, Yang L, Jiang J, Ou Y, Molin S, Qu D (2007) Formation and properties of in vitro biofilms of ica-negative Staphylococcus epidermidis clinical isolates. J Med Microbiol 56: 83-93.

Rodriguez-Carvajal J (2001) Recent Developments of the Program FULLPROF. Commission on Powder Diffraction (IUCr) Newsletter 26: 12-19.

Schlegel U, Perren SM (2006) Surgical aspects of infection involving osteosynthesis implants: implant design and resistance to local infection. Injury 37 Suppl 2: S67-73.

Stähli C, Bohner M, Bashoor-Zadeh M, Doebelin N, Baroud G (2010) Aqueous impregnation of porous betatricalcium phosphate scaffolds. Acta Biomater 6: 27602772.

Steffen T, Stoll T, Arvinte T, Schenk RK (2001) Porous tricalcium phosphate and transforming growth factor used for anterior spine surgery. Eur Spine J 10 Suppl 2: S132140 .

Sudarsanan K, Young RA (1969) Significant precision in crystal structure details: Holly springs hydroxyapatite. Acta Cryst B25: 1534-1543.

Tadic D, Epple M (2004) A thorough physicochemical characterisation of 14 calcium phosphate-based bone 
substitution materials in comparison to natural bone. Biomaterials 25: 987-994.

Trampuz A, Zimmerli W (2006a) Antimicrobial agents in orthopaedic surgery: Prophylaxis and treatment. Drugs 66: 1089-1105.

Trampuz A, Zimmerli W (2006b) Diagnosis and treatment of infections associated with fracture-fixation devices. Injury 37 Suppl 2: S59-66.

Van Blitterswijk CA, Bakker D, Grote JJ, Daems ThW (1986a) The biological performance of calcium phosphate ceramics in an infected implantation site: II. Biological evaluation of hydroxyapatite during short-term infection. J Biomed Mater Res 20: 1003-1015.

Van Blitterswijk CA, Grote JJ, De Groot K (1986b) The biological performance of calcium phosphate ceramics in an infected implantation site: I. Biological performance of hydroxyapatite during Staphylococcus aureus infection. J Biomed Mater Res 20: 989-1002.

Van Blitterswijk CA, Grote JJ, Koerten HK, Kuijpers W (1986c) The biological performance of calcium phosphate ceramics in an infected implantation site III: Biological performance of $\beta$-whitlockite in the noninfected and infected rat middle ear. J Biomed Mater Res 20: 1197-1217.

Van de Pol GJ, Sturm PDJ, Van Loon CJ, Verhagen C, Schreurs BW (2007) Microbiological cultures of allografts of the femoral head just before transplantation. J Bone Joint Surg B 89: 1225-1228.

Vogely HC, Oosterbos CJ, Puts EW, Nijhof MW, Nikkels PG, Fleer A, Tonino AJ, Dhert WJ, Verbout AJ (2000) Effects of hydroxyapatite coating on Ti-6A1-4V implant-site infection in a rabbit tibial model. J Orthop Res 18: 485-493.

Westas E, Gillstedt M, Lonn-Stensrud J, Bruzell E, Andersson M (2014) Biofilm formation on nanostructured hydroxyapatite-coated titanium. J Biomed Mater Res A 102: 1063-1070.

\section{Discussion with Reviewers}

T. Moriarty: Whilst accepting the authors' statement that extrapolation of in vitro data to the clinical situation is difficult, the results presented in this study nevertheless reveal a measured difference in bacterial biofilm formation between the test materials. This begs the question "How much importance should a clinician place on these results?". Are the authors able to draw on any examples of in vitro data of bacterial adhesion or biofilm formation on any material that has successfully been linked with clinical infection?

Authors: The reviewer raises two important points: First concerning the clinical relevance of our presented data. In the initial submission we draw the conclusion that the use of cyclOS can be advocated from the in vitro data. We toned down this statement due to the fact that so far in vivo data are missing (Geurts et al., 2011, additional reference). However, it seems reasonable to use cyclOS instead of another tested CaP scaffold in cases with an increased risk of infection.

Concerning the second point, we recently published data on infection rates, biofilm formation and recurrence rates after lesser toe surgery comparing stainless steel and titanium Kirschner wires and were able to show superior results (lower recurrence rates, less biofilm formation, less clinical infections) for the titanium wires (Clauss et al., 2013). These data confirm the in vitro (Arens et al., 1996; Harris et al., 2007, additional references) and animal experimental findings (Harris et al., 2007, text reference; Melcher et al., 1996; Johansson et al., 1999; Sheehan et al., 2004; Moriarty et al., 2009, additional references) published for these two materials. Furthermore we found some evidence that clinical infection on cerebrospinal fluid catheters is comparable to in vitro and in vivo data (Bayston and Lambert, 1997; Pattavilakom et al., 2006, additional references).

However, the question remains "How much importance should a clinician place on in vitro data or results obtained from animal models?" In a recent review on S. aureus osteomyelitis and animal models published, the authors clearly showed the limitations of various animal models concerning the transfer from animal data to the clinical situation (Reizner et al., 2014). We think that choosing a certain material instead of another will not solely solve the problem of implant-associated infections alone but might be one step in reducing the number of infections.

T. Moriarty: In some clinical studies it has emerged that a significant proportion of bacteria that cause device-related infections are weak biofilm formers in vitro, yet are capable of causing biofilm infections on indwelling devices in human patients. Do the authors have any comment on this, or any data from tests of their materials with weak biofilm forming strains?

Authors: Biofilm formation is a multi-step process with some of these steps even running in parallel. The amount of biofilm formed on the surface thus is not only dependent to the capability of a bacterial strain to form biofilm or not but also on the specific environment. We do not have any additional in vitro data on biofilm formation with weak biofilm forming strains on the surface of the investigated CaP scaffolds.

\section{Additional References}

Arens S, Schlegel U, Printzen G, Ziegler WJ, Perren SM, Hansis M (1996) Influence of materials for fixation implants on local infection. An experimental study of steel versus titanium DCP in rabbits. J Bone Joint Surg Br 78: 647-651.

Bayston R, Lambert E (1997) Duration of protective activity of cerebrospinal fluid shunt catheters impregnated with antimicrobial agents to prevent bacterial catheterrelated infection. J Neurosurg 87: 247-251.

Clauss M, Graf S, Gersbach S, Hintermann B, Ilchmann T, Knupp M (2013) Material and biofilm load of K wires in toe surgery: titanium versus stainless steel. Clin Orthop Relat Res 471: 2312-2317.

Geurts J, Chris Arts JJ, Walenkamp GH (2011) Bone graft substitutes in active or suspected infection. Contraindicated or not? Injury 42 Suppl 2: S82-86. 
Johansson A, Lindgren JU, Nord CE, Svensson O (1999) Local plate infections in a rabbit model. Injury 30: 587-590.

Melcher GA, Hauke C, Metzdorf A, Perren SM, Printzen G, Schlegel U, Ziegler WJ (1996) Infection after intramedullary nailing: an experimental investigation on rabbits. Injury 27 Suppl 3: SC23-26.

Moriarty TF, Debefve L, Boure L, Campoccia D, Schlegel U, Richards RG (2009) Influence of material and microtopography on the development of local infection in vivo: experimental investigation in rabbits. Int $\mathrm{J}$ Artif Organs 32: 663-670.
Pattavilakom A, Kotasnas D, Korman TM, Xenos C, Danks A (2006) Duration of in vivo antimicrobial activity of antibiotic-impregnated cerebrospinal fluid catheters. Neurosurgery 58: 930-935.

Reizner W, Hunter JG, O’Malley NT, Southgate RD, Schwarz EM, Kates SL (2014) A systematic review of animal models for Staphylococcus aureus osteomyelitis. Eur Cell Mater 27: 196-212.

Sheehan E, McKenna J, Mulhall KJ, Marks P, McCormack D (2004) Adhesion of Staphylococcus to orthopaedic metals, an in vivo study. J Orthopaed Res 22: $39-43$. 